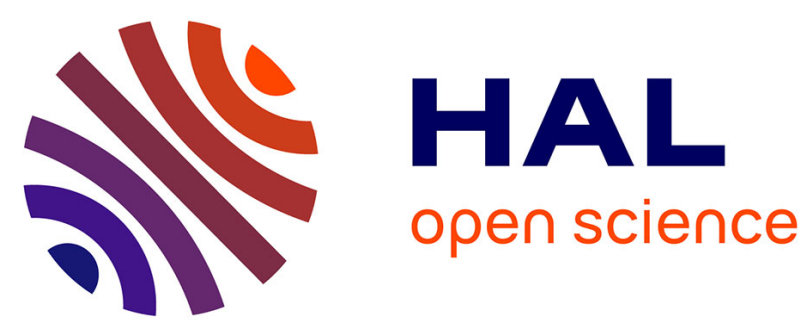

\title{
Computers and School: Indian and French students' discourse
}

Jean-François Cerisier, Aruna Popuri

\section{To cite this version:}

Jean-François Cerisier, Aruna Popuri. Computers and School: Indian and French students' discourse. European Journal of Education, 2011, 46 (3), pp.373-387. 10.1111/j.1465-3435.2011.01486.x . hal01184758

\section{HAL Id: hal-01184758 \\ https://hal.science/hal-01184758}

Submitted on 17 Aug 2015

HAL is a multi-disciplinary open access archive for the deposit and dissemination of scientific research documents, whether they are published or not. The documents may come from teaching and research institutions in France or abroad, or from public or private research centers.
L'archive ouverte pluridisciplinaire HAL, est destinée au dépôt et à la diffusion de documents scientifiques de niveau recherche, publiés ou non, émanant des établissements d'enseignement et de recherche français ou étrangers, des laboratoires publics ou privés.

\section{다)(1) $(5$}

Distributed under a Creative Commons Attribution - NonCommercial| 4.0 International 


\title{
Computers and school: Indian and French students' discourse
}

\author{
Jean-François Cerisier \& Aruna Popuri \\ University of Poitiers, France; Euromime, an Erasmus Mundus Consortium
}

Corresponding author: Jean-François Cerisier, Laboratory of Learning Media Resource Technology (IRMA - ERT 2001), Université de Poitiers, MSHS, 5, rue Théodore Lefebrve, 86000 Poitiers, France. Email: cerisier@univ-poitiers.fr.

\section{Document submitted on 22 October 2010}

\begin{abstract}
:
The use of digital technologies by young people as well as the impact of e-learning have been the subject of a significant number of research studies carried out all over the world. However, when it comes to student perceptions about the place and role of these technologies in their lives, research looks towards university students. This paper aims to understand what the technologies represent for school students, in their personal and school lives. It is based on a study that brings together two contexts, representing opposing cultures and trends: France where the policy on school computers has been in place for more than two decades and India where the government has only recently begun to make efforts to overcome the digital divide in the country. This contrastive study conducted in the two countries in 2009 among 960 young people aged between 11 to 18 years, shows the importance of schools in constructing private spaces to be shared with peers, a role that has long been attributed to home computers. This paper thus furnishes elements of explanation for the relative disenchantment that the young people feel for the school-related usages of the technologies. For these young people, school is not about individualist autonomous learning, it is about learning from teachers as a group.
\end{abstract}

Key words: Information and communication technologies; Young people; Digital culture; School; India; France

\section{Introduction}

Computers are expected to revolutionize classroom environment - change the way the children learn.

This line of thought started taking root essentially with the advent in early 1980s of BBC

microcomputers that made the computers compact enough to be kept on a desk though experiments in science teaching software gave a glimpse of possibilities even earlier (Newton \& Rogers, 2001).

Governments have since spent enormous resources to equip classrooms with computers and to train 
teachers to use them. Developing nations believe that they are being left behind by not equipping their classrooms with computers and are now intensifying efforts to overcome this digital disparity. Despite all these efforts, the use of computers cannot be termed as generalised, even in the richest countries. For nations that have been using computers at school for a long time like France where the first computers were installed almost a quarter of a century ago, it is time to assess the current situation in terms of their real impact in the lives of the children as it is time for nations like India which are just beginning to equip their schools with computers to look into what they wish to do with these computers at school and how it can be achieved.

The research conducted thus deals with two completely different contexts: a developed country like France and one which is still on the way to development like India. The Indian education system, given its massive proportions, demonstrates a large disparity between Government schools and the private schools in terms of equipment and use. In the much sought-after expensive private schools catering to the upper middle class, courses in the basic principles of computers were started at around the same time as the French. On the other hand, government schools, which cater to $72 \%$ of the schoolgoing population, are being equipped with computers under a scheme introduced in 2005-06. At these initial stages of policy formulation, where terms like autonomous learning and child-centric teaching practices are beginning to be applied to the colossal public school system, it is pertinent to look into the impact of computers on this system.

In France, after several equipment drives and teachers' training programmes backed by highly favourable government policies, the highly centralised French school system has deemed that the ICT shall not be a subject to be taught separately but used as a teaching tool that would be integrated into other subjects by the teachers. Comprehensive digital work environments have been introduced. But usage at school of these new technologies has not led to the expected results. Lack of enthusiasm or skills among the teachers or even lack of proper equipment has been considered for long to be the main reason. A study conducted by Clemi (Bevort \& Breda, 2006), introduces a new dimension by demonstrating that school children who are otherwise avid users of computers are not equally enthusiastic about using these at school. A more recent study (Smart Technologies, 2007) states: 
" $97 \%$ of the teachers and $89 \%$ of the students use a computer at home while it is only $55 \%$ of the teachers and $26 \%$ of the students who are using it in their school!"

Thus the teacher motivation seems to be less of an issue than that of the students. This is the aspect that our study will be working upon. Moving away from the usual practice of asking adults to explain how children react to computers at school, this paper aims to explore uniquely the perspective of the students, who are supposedly the final beneficiaries of these computers at school, as to the impact that these school computers have on their personal and school lives in both the Indian and the French contexts.

Thus the questions before us are: What is the dynamics of the students' relationship with the computer at school and how does it differ from the relationship with computers in general? For understanding this, we also need to look into the relationship that the child has with the school, i.e., we need to understand the dynamics of a school, from the point of view of the student-youngster.

\section{Methodological concerns}

The first concern is related to the fact that the questions are being asked to children or rather adolescents and not adults. The intention is to understand how the young people live their experiences from their own point of view, something that only a few studies like Mediappro, UKChildren go online venture out to do.

In the first stage of our research, a survey was carried out with a population of Indian (621 usable responses) and French school students (339 usable responses) in the age group of 11 to 18 . The survey made it possible to collect, in addition to the factual data on the use of the school computer by the students, elements pertaining to their representations of the school, the computer at school as well as outside the school. The survey questionnaire consisted of 111 items, 109 close-ended questions and 2 open-ended ones. It was subject to a double validation: by submission to a panel of experts and as per a consistency test with the responses received from a group of 30 students (Crombach's $\alpha=0.714$ for the entire questionnaire). As a second step, 47 interviews were carried out to understand further the representations of these young people (24 in India and 23 in France). The students participating in the 
second step were chosen to represent the four categories defined by the two variables "I like school" $(+/-)$ and "I like computer at school" (+/-). Data from other researches conducted by the authors of the article and otherwise, have been used to complement our study with the sources mentioned wherever necessary.

The next concern is the manner in which the two different contexts are to be addressed. Some studies like Pisa study (OECD, 2008) involve comparison of various groups or countries on the basis of certain criteria determined beforehand by the researchers. The analysis of the responses invariably leads to a comparison of the various populations being studied, a ranking determined to indicate how each of the populations being studied fares in terms of what the researchers determine as being representative of an "ideal" situation. In our study, the intention is not to compare the two contexts, which have been chosen essentially because of the vast divide that exists between the two, in all aspects. It is thus a "contrastive" study or a study of the contrasts. This process facilitates an understanding of each of the systems in its entirety by highlighting the differences between the two.

Continuing in the same contrastive perspective, given that the authors are a team of two researchers coming from the two contexts of the study, India and France, it was decided that the French system will be analysed by the French researcher and the Indian context by the Indian researcher with both of them working together on the perspective analysis of the situation of the two countries. This leads to a difference of style and analysis, which is in keeping with the contexts in question. While in France, these issues have already been subject to several studies, leading to a more profound analysis, in India, there are few studies on the representations of the young, let alone their representations pertaining to the computers at school. Hence in the Indian context, we look at the results obtained from the study more in detail while in the French context, it is more integrated with the current theoretical concerns. The conclusive parts of the article are enriched by analytical elements provided by both the authors, each looking at the contexts with a perspective arising from one's own context. 
Thus, in the first part of this article, an analysis of the Indian system will be presented followed by a section on the French representations. In the final section, the two systems will be juxtaposed against one other to give us the concluding elements of contrast to be retained for both the contexts.

\section{Indian context}

In India, there is a diversity of school contexts based on geographic situation and the funding received: urban / rural, public / private, English-medium / vernacular-medium, mainstream / alternative, madrasahs / convents etc. We will be particularly concerned with the public-private divide which can be further classified into other fragments: the public schools divided into government schools, government aided schools receiving upto 95\% funding from the government. In Government schools, the admission is free of cost and in the Government-aided schools, the cost of education remains very low. Hence these schools cater to a population that cannot send their children to the private schools, which have a better reputation, in particular, due to the fact that these schools offer English language classes. The private sector represents schools which don't receive any aid from the government: lower income private schools and more elitist private schools that cater to the higher income groups. These schools have to, however, obtain recognition by the government. While the public sector caters to $72 \%$ of the population, the private unaided sector caters to 28\% (Ministry of Human Resource Development, 2008).

As indicated before, a population of 621 Indian school students between the age group of 11 to 18 years responded to the survey questionnaire. The responses came essentially from two school contexts - the elitist private schools (46.5\%) and the government aided schools (50.1\%), catering essentially to students from an urban background. There are some responses from the other contexts such as lower income private schools $(1.4 \%)$ as well as the government schools $(1.8 \%)$ from the rural areas near Delhi. However, government aided schools are considered to be quite similar to government schools (Ministry of Human Resource Development, 2008). Though this may be true, for this study, we shall consider students from both these groups as one. Thus our study can be considered as representative of essentially the two said contexts of elitist private schools and the government aided 
schools situated in urban Delhi. The questionnaire was followed by interviews of 24 students from these two groups in three schools.

Let us now explore further as to how computers are dealt with in each of the different kinds of schools where we carried out interviews as part of our study. In the first school, which is a governmentaided school with a large percentage of students from lower middle class background, there is only one computer lab with 30 computers. The entire class usually composed of 30 to 40 students go as a group for the computer classes to the computer lab. Some students used to play games here, which are now banned. There is no Internet facility except on one computer, which is frustrating as one student puts it, especially when they learn to create a website but cannot really see it functioning on the Internet.

The second school is a private school, which caters essentially to children from upper middle class to wealthy families. There are computer labs with Internet but again, the entire class (composed of 30-35 students) goes to work on computers during the computers class and work in pairs. Apart from that the students are allowed to use the computers for their personal use during lunch break. But getting access is very difficult with usually a long discouraging queue for a few minutes of playing games or accessing social network sites like Facebook or Orkut.

The third school is a well-known private boys boarding school, which has some of India's political and business elite among its alumni. The school has state-of-the-art computer facilities with high-end servers and generalised broadband connection. "There are over three hundred computers, spread over two computer labs, the library, the five houses and most classrooms". But this is a special case especially because the school is a boarding school and Internet is now a recognised means to communicate with family and friends at home. Students are allowed use of laptops at the senior level. Most socialisation sites such as Gmail, Facebook etc are blocked essentially to protect the server from getting jammed due to overuse. But some students are able to circumvent these prohibitions to access these sites.

It is indeed very interesting to note that there is a sort of constant combat between the student community and the administration in all the three schools. In the first school, it pertains to merely 
permission to play games like Solitaire etc., in the second it is about downloading certain games on the computer and in the third, it pertains to access to the socialisation sites.

\section{Computers and social divide}

In India, often the school one goes to is determined by and determines the social context of the child. A rich child would rarely be seen in a government school that caters to 72\% (Ministry of Human Resource Development, 2008) of the school-going community in India. A child coming from a lower income background would rarely be able to go to the much sought-after elitist private schools (Kingdon, 1998).

This social divide goes on to manifest itself in terms of access to computers at home or at school. $81.3 \%$ of the students who responded to the questionnaire have access to a computer at home As it was revealed during the interviews, a computer at home could also mean a computer at the neighbour's home or at a close relative's place which can be considered as being "at home" since the demarcation between immediate family and close relatives and neighbours can be quite blurred in India. This could be one of the reasons for such high figures of computer ownership. The disparity between the different backgrounds is also evident from the fact that $1 \%$ of the elitist private school students don't have access to a computer at home whereas it is the case for $34.1 \%$ of the students from other schools.

As we have seen, the social divide pertaining to the computers at home extends somewhat to the question of computers at school. Though the elitist schools have a better computer-student ratio, the use that the computers are being put to is not necessarily very different. The elitist school students are more positive about computer classes than the students from the government-aided schools (Table 2). While in the elitist schools, the software is taught with a more innovative task based approach, the government schools stress more on the theory and practice is usually left incomplete due to lack of good internet connection. This being so, the computers are rarely used in either case as a teaching tool, though a few students, having read some material on it, would like it to be used as one. In the government schools as well as in the elitist private schools, computers are taught as a separate subject with a common curriculum set by the central agency NCERT (National Council for Educational Research and Training) which includes the basics as well as software programs and even computer languages. It 
has been noted that those who don't have a computer at home or those who don't have free access to a computer are more likely to learn to use the computer at school. On the other hand, those who have exclusive access to a computer learn mostly by themselves. The school hence clearly contributes to reducing the digital divide as is desired by the policy of the Ministry of Human Resource Development (which is the name for the ministry looking after the education).

The disparity in ownership and exclusivity also leads to a disparity in the activities being carried out by the various groups. The usage is much more limited for government aided school students except when it comes to games under personal work at home and multimedia files as part of school work at school (Figure 1) ${ }^{1}$. For some activities such as chatting, which require high level of Internet access for the teenager as well as his or her friends, there is a difference between those with exclusive access to the computer and others. Chatting among the less disadvantaged sections is done essentially with friends whom they cannot meet anymore such as those who have moved away to a different school. But students from the better economic backgrounds also chat with the friends whom they meet every day at school. Apart from chatting, one of the main activities is to look for information on the search engines for homework. In addition to searching for information, the effect of the computer at school can be seen essentially in the use of various software such as Paint, Photoshop for creative activities and/or Word etc. for doing project work or school assignments.

\section{Real vs. Virtual:}

The students are often asked by their teachers to write reports on various issues and not given enough time to do so. The best way to get the information required for them is to look it up on the Internet. Those who don't have a computer at home have the option of going to an Internet café or get someone in the family (father in one case) to get the information they need. In fact, it is only when it

\footnotetext{
1 The coefficient is calculated for each activity in four different situations (personal work at home, schoolwork at home, personal work at school and schoolwork at school) by according weightage to the time spent (Not at all=0, Less than $30 \mathrm{~min}=1,30 \mathrm{~min}-1 \mathrm{hr}=2,1 \mathrm{~h}-2 \mathrm{~h}=3,2 \mathrm{~h}=4$ ).
} 
comes to books that they prefer the computers because of the instantaneous and easy access to information as compared to the books. Despite this preference, the students are quite aware of the disadvantages of this easy source of information - textbooks contain comprehensive information with the details that they require while computers can lead sometimes to wrong or incomplete information.

According to the students, the physical presence (Weissberg, 2000) is preferable to a virtual presence though the virtual is getting closer to the real with new technology like web cameras, etc. But this very reduced physical presence can also be an advantage. As one student puts it, "it is easier to say things in front of a computer". Another student explains that there is only one sense active instead of the confusion created by all the senses in real life, which makes interaction simpler. According to another student who chats with strangers on internet, it is the honesty that comes with the anonymity that makes it possible to interact on a variety of themes, thus taking one out of the daily routines. Given that much of the real private time and space of the young people is controlled by the adults, i.e., the parents at home and the teachers at school, the technologies offer to these youngsters, a virtual private space while continuing to be physically present in the controlled space (Boyd, 2007).

Thus a computer for these young people is essentially a tool for fun or a useful tool that one can get easily addicted to and which could cause health problems in case of overuse. Parents encourage them to use it, especially girls even though they might be prevented to go out with their friends. They feel that they might get bored without computers but it remains a pastime that can be replaced. The virtual, for these students, comes after the real. Real games and interactions are preferred when it comes to friends whom they meet regularly.

\section{Schools - not just centres of learning}

The Indian students have a positive representation about the school, whatever be the kind of school the child might come from. When asked the question whether they like school or not, about $73 \%$ say that they like school but this popularity doesn't seem to be related to the activity that takes up most of their

time at school, attending classes. Students, especially from the economically favoured classes, don't like 
this activity. However, the interviews reveal that the relationship that children have with school is an extremely complex one, once again irrespective of their economic background. Most say that they like school "in all its domains", some like and don't like at the same time and some others, not at all. It all depends on the "mood of the day". The mood can be different at different moments of the day. According to one student, "Even when I don't feel like coming to school, I come and then I feel good". Another one says, "I like [school] but sometimes I don't feel like going to school". Even when it comes the classes that less than $10 \%$ really enjoy (Table 2), that they are forced to sit in, they accept the situation saying that "it is good for them because they learn something even without wanting to". While the lack of freedom is not really appreciated, the positive aspects of the same convince them to continue going to class.

The reasons for going to school (Table 3) are not the same as what is keeping them there or keeping them happy to be there. They go to school for various reasons of which learning is the most important, whether it is about getting knowledge, or learning behavioural issues, learning to live in a society, etc. The socialisation aspect - meeting friends or more generally speaking, people outside of the family circle - is an important reason as well. The prospect of a better future mentioned by Anita Rampal (Rampal, 2005) also has been mentioned by around 10\% of the students (Table 3)

As for the positive aspects of the school (Table 4), it is the socialisation that comes first: being with others and getting to know people. School, while ostensibly advertised as a place to study, offers them an opportunity to have their own private space and time to indulge in activities with their peers without any adult intervention. The time they spend in interacting with their peers, whether in a class or outside a class, seems to be one of the most important activities for them. Likewise, during the sports class, they have much freedom to indulge in a physical activity with little or no supervision.

But while the importance of having friends is largely highlighted, the problems with some peers are considered a negative aspect of school. Whether positive or negative, this relationship with peers is definitely one of the most important aspects of this phase of life. As put across by a student from an elitist school, the social structure of a school is like the society that we live in, albeit with its known rules. "If you have the correct personality, you can get anywhere in your school life. But if you don't have 
the correct personality, even if you are pretty, even if you are beautiful, even if you are rich, you will never get anywhere. Its only the personality that makes you". These relationships with one's peers are not governed by total freedom nor by the "tyranny of the majority" that Pasquier (Pasquier, 2005) talks about. Some students, surprisingly, cite the lack of respect for the teachers as one of the factors of this bad feeling vis-à-vis certain classmates. Which leads us to the complex relationship with the teachers.

Officially, the teachers have all the power in a classroom. Some students even claim to have been unjustly punished by them. More than the actual punishment, it is the fact that they are punished in front of the others that bothers them, which might or might not be what the teacher is aiming to do. Some admit to being intimidated by the teachers. The punishments are varied: from asking students to leave the class to asking them to remain standing or even hitting the students event though it is prohibited to do so. And yet, the students show a very strong social influence by insisting upon the fact that one "must respect teachers and accept everything they say". In fact, the students like authoritative teachers. Thus even if they resent the punishment meted out to them at that moment, they accept it. But they don't want teachers who are too authoritative. "They should listen more to the students". They admit to poking fun at the teachers and yet, they feel the teachers deserve respect due to the simple fact that they are older to them. All in all, they appreciate "the effort that teachers make to teach them". They feel that thanks to the teachers, they push themselves to study.

The teachers are however not considered to be the only reason for liking or disliking classes that corroborates an ethnographic study conducted in a private school in 1985 \& 2005 (Thapan, 2006). Several of them state that they like some classes and hate some. The subject being taught is a factor that we are aware of. But some come up with the fact that it also depends "on the day". Some days, you like classes and some days you don’t. As one student points out, “I often feel sleepy in the history class. Sometimes, however, I find it so interesting to know what happened in our past". The reason for this can be found in what one student indicated: it is "impossible to remain attentive the whole day". They are thus sometimes present physically and yet absent mentally. They think of other things. This phenomenon, however, is not limited to students alone (Jacquinot-Delaunay, 2000). When one is listening to someone speaking, the mind can and does wander, whether it is children or adults. But most 
students are happy not to have the freedom to do what they want in class. They want to learn discipline, which is considered extremely important for the future adult life.

Such is the rich and immensely complex nature of what school has on offer for the students. The school is mix of several aspects, acquisition of knowledge, socialisation away from the home context, building of one's character, etc. For the students, life without school would be impossible, thus rejecting Ivan Illich's theory of "Deschooling society". In such a scenario, where it is clear that for students, school is not merely a place of learning, what kind of impact do the computers have?

\section{Classes are certainly more interesting with computers but...}

Everyone agrees that the computer make classes interesting though there is no evidence of the use of computers as a teaching tool in any of these schools. There are of course computer science classes where the computers are used, to various degrees in various schools. A majority would like the use of computers to increase but there are also those who don't like to use computers at all and don't see any use for them at school.

According to the students interviewed, the computer at school has essentially two major contributions apart from the macroscopic impact of reducing the digital divide. The first is the opportunity of learning computer languages that might help them to become computer engineers in the future. Thus it is expected to have an impact on their careers.

The second contribution is the impact on the way the computers classes are conducted. They write less, teachers speak less. The classes are more fun. Those who are bored in class are generally more interested. One is more active. But this interest in computers gets limited to a mere "change from the routine". Instead of the usual classroom situation where they are sitting at their desk listening to a teacher giving a lecture, they are doing something on the computer.

Despite this positive influence, the school computers evidently have a limited impact on their school life. Even on the computers they have to do activities defined by the teachers and follow their instructions. This seems to make the activity much less fun than them using the computer all by themselves without anybody's intervention. It is at home that they experiment and try out new things, 
not at school. Their intuitiveness is more at play at home since they have to find things out by themselves while at school, they are "taught" to carry out certain functions. Thus, the students are hardly autonomous in their learning even with the use of computers. They also feel that "if the use of computers during class were to be increased, it would become normal and thus boring". They are also aware of the negative impact of using computers on their spellings, health etc. They would definitely be bored if there were no computer at school but then the school has so much more to offor that they would still like to come to school.

The ideal situation for many: a mix of classes with computers and without computers where the teacher dictates notes. They don't want to use the computer all the time in class, thus completely rejecting the principles of "one laptop per child" programmes. Computers at school are not a very important issue for the students.

The reaction to the computers at school seems to correspond to this feeling of lack of enthusiasm for studies, thus confirming what a French educationist Devauchelle calls "scolarisation" of everything that enters the school. Computers at school are not the same as the computers at home. The freedom of usage is not there, that is, they cannot do whatever they like in class, nor with the computer. Nor do they really care. They have their friends around; there is so much to do in school. For them, as we have already seen, virtual activity comes only when there isn't any interesting alternative in real life. The Internet is 'scholastic' like everything academic at school, resulting in the same general lack of enthusiasm and resigned acceptance reserved for classes.

Looking further into this issue of scholarisation, the equilibrium that exists in the school system - between personal relationships and educational relationships - is an extremely complex one and shaking up one element can cause an imbalance in the scheme of things. At the moment, the system is resisting the computers, whether it is the teachers who find it extremely difficult to get a group of 30 students and above to "learn" and develop themselves by making them sit in front of computers or the students who are not ready to give up the traditional methodology of a teacher teaching, which allows them to drift in and out mentally while at the same time, picking up some knowledge. A constant effort 
to learn during the entire time they are at school is impossible. For the moment, the computer is a tool for fun. It is a tool for learning too, but it becomes less attractive when they have to do activities on it as per the teacher's instructions. With school already being a hub of social activities, there is no need for a computer to socialise here.

\section{French context}

As far as France is concerned, our research has essentially been conducted among students from four schools in the region of Poitiers: two public junior high schools (grades 6 to 9) and two public high schools (grades 10 to 12). Let us recall that in France, the junior high schools and high schools together constitute the secondary education and deals with students between 11 and 18 years of age on an average. At the junior high school (11-14 years) (Ministère de l'Éducation nationale, 2009) called unique, all the children follow the same syllabus. On the other hand, there are two types of high schools (15-18 years) for students (general and technical education schools on one hand and the vocational schools on the other hand), which propose various streams to the students as per their aptitudes and their future plans. School is compulsory for children in the age group of 6 to 16 years. The overall percentage of school-going children indicates that this objective is achieved: $100 \%$ at 11 years and 95.8\% at 16 years (Institut national de la statistique et des études économiques, 2009). Private schools also exist and cater to around one-fifth of the school-going children. These are almost always associated with the State, by way of a contract, which guarantees that the national syllabus is followed and the teachers' educational qualifications are equivalent to those in the public sector. While the pedagogical practices and the level of equipment are very similar in the public and private systems, differences are seen more in terms of sociology and recruitment but these schools will not be part of this paper. There is a good contrast between the four schools retained for the research and a fairly complete representation of the French school-going youth today is obtained. During the survey, 339 usable responses were collected and 23 interviews were carried out to explain and explore further.

\section{When the domestic equipment takes precedence over the school equipment}

The results of our study corroborates, to a large extent, other equipment-related studies that have been carried out in France over the last few months and in particular the work done in October 
2009 by the French survey firm TNS-SOFRES on behalf of the National Union of Families (UNAF in French) and the Association Action Innocence (TNS-SOFRES, 2009). Just like our study, this study, carried out on a large scale with a stratified sample corresponding to the requirements of the inferential statistics, confirms the young people's penchant for multi-equipment acquisition. Thus $87.6 \%$ of the students in our sample have a computer at home. This includes $40 \%$ who have a computer reserved only for their use. At the same time, these young people have other digital gadgets (MP3 players, game consoles, photographic cameras...) with the mobile phone playing an important role at the top of the list. Computer, Internet, mobile phones have rapidly taken an important place in the lives of the young, as much through the activities as through the time that spent on them. Their gadgets are modern and fairly often in contrast with the equipment at school which, though not totally outdated, is generally older and above all, smaller in number. While nearly two-thirds of the young declare that they use a computer at least once a day at home (78\% of them use it several times during the day), the usage at school, whether for school or personal work, is clearly less frequent (Europe's Information Society, 2006). As for the level of the services used, the little said the better it is. Evidently, the school applications hardly resemble the sophisticated services that they are accustomed to using for their personal work (instantaneous messaging, music broadcast platforms, videograms...).

\section{Usages at the confluence of the places and the objectives pursued}

In order to analyse usages, we chose to categorise the situations by considering the young people in the plurality of their social existence. Following the example of the plural man described by Bernand Lahire (Lahire, 1998), the didactic contract (Brousseau, 1988) that connects them to the school makes students out of them, the family cell conceives them through family relationships mainly as children, grandchildren, brothers or sisters and the construction of their affinity-based networks position them in terms of friendships. We have thus distinguished four situations by crossing the place (home / school) and purpose (school / private) of usage. Analysed in this manner, the behaviour of the young people varies greatly, at least according to what they say. It must first be noted that the place of usage constitutes their framework of action as is defined by Bateson (Bateson, 1972), it is actually less normative than what the adults think. Thus, students are not merely students when at school nor do 
they leave behind the role of a student at the school gate. The different dimensions of the individual are reconstituted according to the situation and the technologies are greatly mobilised in these dynamics. The term "poaching" as proposed by Michel de Certeau (Certeau, 1984), could be used to describe the liberties taken by the users of a device with respect to the intentions of their promoters. The students today do not really conform to the injunctions by the adults or their elders and several testimonies that underline a real appropriation of the technologies at school can be found. Since the legitimate adult precautions are such that "we don't have the right to go on MSN", "we don't have the right to go to game sites" and finally, "we don't have the right to do anything much", then the student reaction is such that, "we don't have the right but we do it anyway", "a game was downloaded without anyone realising it" and in any case, "there are sites that are blocked but not all of them". And what applies to school is also applicable to home where the margins of freedoms are easier to conquer, as is expressed by one of them for whom, at school "there are things that we have to do and those that we shouldn't do while at home, we can practically do whatever we want". The usage mapping using data obtained from the survey shows interesting characteristics that are notably different from the results obtained in a preceding study conducted 7 years ago, partly in the same schools (Bernard \& Usé, 2003). While the students essentially used the computer to communicate with their peers, today they give more importance to searching for information, except in the modality of domestic usages for schoolwork. What seems paradoxical can be explained by two main evolutions. On one hand, there has been a massive movement of communication-related activities from the computers to the mobile telephones, the only gadget that is truly nomadic and personal. A study published on 21 July 2010 by ComScore, a company specialising in marketing research, illustrates this swing among 15-24 year olds from the computers towards the mobiles (ComScore, 2010). On the whole, the usages, measured in terms of frequency as well as duration, witness a fall in the case of computers while they are on the rise as far as mobile phones are concerned. On the other hand, the formal search for information, which is strongly supported and promoted in schools, notably with the help of librarians who teach the students how to do it, is different from networking and collaborative activities, which prevail from the moment the school fades away. This is why instantaneous messaging becomes the best ally for schoolwork done at home. MSN, the 
instantaneous messaging application that was the most cited in our survey, thus makes it possible to communicate with fellow students once back in the family home, not only for friendly talk or love talk, but also in the case of studies, "if we don't understand some work, we can ask" or better still, "we try to find out together".

\section{School, a necessary evil}

The young people who were questioned do not manifest systematic opposition to the authority of the adults, something which they are often accused of doing, notably with respect to the school but they are not, for all that, very enthusiastic about it either. While only $30 \%$ of the students of our sample say that they like school (from $58.5 \%$ in first form to $19 \%$ in sixth form), $47.3 \%$ choose learning as the primary reason for going to school $70.7 \%$ choose learning among the two main reasons for going to school and $88.5 \%$ among the three main reasons) while the socialisation activities with their peers which one can imagine would be the first reason for wanting to go to school only gets the third position (as first choice) with $12 \%$ of the students and accumulates $84 \%$ among the three first positions. Effective and to the point, 13 year-old Sonia's analysis is an eye-opener: "I like and I don't like school". Others, during the survey as well as the interviews, confirm this awareness of the importance of the role of school in their personal trajectory. We are finally quite far from the supposed irresponsibility of the "youth culture" as described by Parson (Galland, 2003).

\section{The profound significance of the technologies for the young}

Explaining away the passion that the young people feel towards technologies by merely mentioning the massive diffusion of these in all the sectors of human activity seems to us as being equivalent to denying their capacity for appropriation based on their intentions and desires. Mark Prensky's purely descriptive hypothesis based on the immersion of the new generations in an environment saturated with technologies does not have a convincing explanation (Prensky, 2001) and the adhesion of the young to the technologies cannot be assimilated to their consumerist behaviour in the face of an economic system with a particularly efficient marketing. These two dimensions obviously contribute to the success of the technologies in this section of the population but these are perhaps not sufficient enough to explain it. Our research highlights the importance that these young people attribute to the 
technology in the way they conduct their social life. It seems to us that they first mobilise technologies in order to re-conquer a strictly private individual or community space, which the evolution of the French society deprives them of elsewhere. The construction of public spaces doesn't take into account the needs of the young and even if their aptitude for changing things to their advantage helps them to appropriate spaces that are initially not meant for them (entrance halls of buildings, movement areas in commercial spaces ...), the chronic deficit of space dedicated for their specific use cannot be ignored. Likewise, the agenda of the young is very heavily constrained by obligations of all kinds whether it is school activities or other activities prescribed and/or controlled by the family (family life, sport, afterschool activities...). The technologies then appear not as an alternative but as a means for the emancipation of the young. And they use it to this end very coherently. Thus, in their eyes, the mediabased communication does not replace the face-to-face interaction but substitutes it when being physically together turns out to be impossible. This is what happens when they are back in the family fold in the evening, when they are doing their schoolwork as it has been mentioned above, as well as when they are in class. When a computer is used in class, "...sometimes, when the teachers have their back to us, we can go to $M S N^{\prime \prime}$. In the absence of the computer, it is the telephone, which makes the communication possible. The TNS-SOFRES survey cited hereinabove, has shown that more than half the high school students say that they use their mobile phones during classes. At home, the digital communication tools are used for more personal conversations, including with other young people who go to the same school. In fact, “we are not necessarily in the same class. Hence, we don't necessarily have the time to talk to each other". In addition, technology, contrary to the fears expressed, guarantees the confidentiality of the exchanges. "There are so many people at school. They can listen to the conversation", declares a student while on the net, "we can speak only with the person". And the young clearly perceive how the mediatisation of the exchanges affects the mediation, in a way that is sometimes advantageous. "I have more time to reflect on what I am going to say so as not to say stupid things, or things that are not necessarily pertinent", observes one while another student emphasises that for "some issues that are quite tense in real life, there are things that we manage to say more easily on MSN". The distance gives confidence in one-self and in the others "we dare say things on MSN that we 
wouldn't necessarily say when the person is there with us". For the young, the mediatisation doesn't have only advantages. Like Jacquinot (Jacquinot-Delaunay, 2000) they know well that while the physical presence is only one of the dimensions of the presence, it is likely to play a determining role in the relational processes and that the sentiment of presence does not always go very well with Internet. It is clearly this weakening of the signs of presence which is indicated when the young people point out the fact "that we don't see the expression of the person [with whom we are communicating]", "that we cannot kiss each other goodbye on the chat" or "that it cannot replace the true contact with the others".

\section{The rejection of the "scolarisation" of the computer}

While for the young, the technologies are above all perceived as useful for contributing to their autonomy, their reticence with respect to the usage made of them at school is not surprising. Only $40.4 \%$ of them would like the computer to be used in classes while $59.6 \%$ are indifferent. They dread any kind of normalisation of the usages of the computer that would put into question the objectives for which the technologies are so important in their eyes. In fact, there are grounds to look into the school activities using technologies that are rejected by the students and those that they are overwhelmingly in favour of. In the very first place, in their action as in their discourse, it can be observed that they make great use of the technologies for the school activities that they organise themselves, that is, essentially, the school activities that they carry out outside school. The search for information in reference books or other books is largely replaced by Internet. It is simpler and faster, "you type a word and you already have the answer", "in two clicks, its done" and besides, "we don't really have the time to search in the books". Without taking into account the collaborative dimension of the tasks carried out when they find themselves alone in the house but connected to the peers, and they are connected "sometimes just to see if anyone is connected so that they can note the homework". On the other hand, the usage that the computers are put to in class is not really interesting for the students unless it allows them to be active. In fact, while the students recognise the relevance of the classes including those where the teacher simply lectures, especially if "the teacher makes whatever he or she is teaching alive", they estimate that a number of classes are not interesting because "what we don't like to do is to remain sitting on a chair listening to lectures the whole day". In some cases, the recourse to the computer makes 
it possible to remedy the situation since "in a class, it is the teacher who explains while on the computer, it is we who do it". In all the other cases, the computer does not change anything, all the more so because the novelty effect that has a positive impact on the motivation of the students and which is so often cited by the promoters of the computer at school, is legitimately put into perspective by the young people with several of them observing that "if there were more computer rooms or computers in the class, it would become normal after some time". The young people are, even in this case, sensitive to the usefulness of the technologies. For them, it is clearly the nature of the activities proposed to them that is more important than the means used for the same.

\section{Conclusion: A perspective analysis that reveals regularities and singularities}

Positioning oneself from the perspective of a listener listening to what the young people as saying, apprehending their practices and their representations with respect to the computers, offers a point of view that has the privilege of observing the evolution of our cultures in the digital era. The contrastive approach, a concession-less implementation in this research since it relies on two parallel studies analysed by the natives of each of the two contexts, is revealed to be highly heuristic at the moment of putting the results in perspective. The regularities that bring the Indian and the French students together are numerous to the point that a more general process to analyse the results could have been retained as they represent a more globalised youth culture or rather a global school culture. But there are other behaviours that are clearly determined by local culture of each country. Thus, the passion among the young people for community-oriented activities and the possibilities that these offer them for constructing uncontrolled space-time indispensible for their autonomy, whether it is with the computer or without. With these elements having been presented in a rather detailed manner in the analysis specific to each of the two contexts, we have preferred to emphasise on three of the singularities that seem to translate cultural differences that remain pertinent today. These express the profound values of each of the two countries and are anchored in their respective histories while being potential factors determining the direction that education of the young people needs to take. 


\section{Private space and time}

The difference in the overall attitude towards school is something to be reflected upon in France. While the likes and dislikes pertaining to the various activities at school remain more or less comparable among the French and the Indian students, the overall attitude is overwhelmingly negative in the case of France and overwhelmingly positive among the Indian students. So, in the face of the same issues the two groups tend to react differently. We estimate that these differences are essentially due to two factors, the first one being the fact that the French system is stronger and hence more rigid, especially when it comes to marrying the two essential elements of school, fun and learning. But as we have seen, this fun is almost always related to a freedom of interactions with their peers and what we can call a private space and a private time that the students have.

The second factor pertains to the cultural differences in the two countries. In India, restrictions seem to be accepted more easily making the students less resistant to the restrictions that school imposes on them, which are in any case, not as rigid as in France. The parents and the teachers can and do use corporal sanctions sometimes which the young, though they are adversely affected by the same immediately, accept later by identifying the positive impact on them. On the other hand, in France, these punishments have been successfully prohibited with effective support structures against physical abuse. The relationship between the students and the authorities are difficult with incidents of violence reported against the teachers.

\section{A difference of perception of the educative finalities of the School computers}

The practices and the representations that the young have of the computer at school corresponds to three distinct logics that clearly appear from our research. The first one is frequently mentioned in scientific literature. It is emblematic of the educative technologies and concerns the use of the computer for didactic purposes, for learning activities pertaining to all the knowledge and competencies covered by teaching syllabi. The technologies are considered here as means of teaching and learning. The second one is interested mainly in the mastery of the technologies themselves and covers a large span from the most technical skills (programming for example) to media education in its political dimension, in the noblest sense of the term. In this case, the technologies are considered as a subject of learning. The 
subjection links between these two logics are quite well known today. In fact, the effectiveness of the use of technology in learning activities is notably subject to the mastery of technologies by the students. However, this dimension of the technologies at school is subject to a lesser attention by the researchers in the domain. The third logic, very rarely mentioned but on which our research focuses is related to the objectives of the young people themselves which have been shown to be sometimes far from the objectives of the school itself. While the issues coming from the last dimension seem to be experienced in a relatively similar manner in India and France, it is not the same for the first two. For different reasons, India gives much more significant importance to computer science as a subject than in France. The main objective, with which the Indian Government has introduced computers in schools, i.e., overcoming the digital divide, is clearly being achieved if we were to go by the student representations. While the situation is far from the perfect equality, the Government is making an effort to ensure that all the students are able to learn to use computers. This attention is also based as much on a conception of the education in general but also on the more specific role of the school in the construction of a new national economic model. While this is finally a decision that escapes the young Indians, we do find traces of it in the manner in which they apprehend the technologies at school. The computer acquires a status analogous to that of the subjects and evokes an expectation expressed in terms of intrinsic utility of these computer classes that the students consider favourable for the construction of their professional future.

In France, despite a national programme of certification of the competencies of the students pertaining to the usage of computer and Internet, a programme that does not include specific teaching, for the students, the computers at school are there as a means of learning. Overcoming the digital divide is not an objective given the high percentage of students with computers at home. Thus clearly, the main reason for using the computers as means of learning is clearly the conviction that computers change the way the students learn and makes them more autonomous. However, as we have shown in the analysis of the French situation, the young people are all the less inclined towards these technologies as they orchestrate traditional pedagogical practices. Thus the enthusiasm that the students feel for personal activities on the computer cannot and must not be construed as a motivating 
factor for the computers at school. Autonomous learning, though a very attractive concept, must be applied with caution to the school system. This fact combined with the general concern for their future among the young French students makes it necessary for the policy makers in France to look into the possibility of teaching computer skills to the students.

The reactions of the students, Indian as well as French, also justify the reticence that the Indian Government is showing with regard to the proposals for the introduction of "One Laptop Per Child" programmes in India. Having a computer to oneself during school time is not what the students want. They would however like to use one with Internet and for doing activities that they would choose. The motivation for using computers is not translated into motivation for using computers at school for learning activities, especially if the pedagogical practices remain directive in nature. And yet they actually want these traditional teaching methodologies to continue.

To conclude, there is a need to extend this study to the other educational contexts in India, which are in great contrast with the urban contexts that have been explored here. The policy makers would also benefit, both in India and in France, with a study of how the young people make the best of the little gaps that the educational system leaves for them, which they use to create their own private culture and world, a culture and world that they share with their peers. This world, as per our paper, may or may not involve computers. Thus this research about computers at school opens out the path for more detailed study on the construction of private spaces and hence their own autonomous space within a society, which is more and more restrictive in terms of space and time, especially in the case of the young. 


\section{References}

Bateson, G. (1972). Steps to an Ecology of Mind: Collected Essays in Anthropology, Psychiatry, Evolution and Epistemology. Chicago: University of Chicago Press.

Bernard, Y., \& Usé, B. (2003). Internet au collège : une éducation nécessaire. Mémoire de fin d'études du master Ingénierie des médias pour l'éducation . (J.-F. Cerisier, Ed.) Poitiers, France: Université de Poitiers.

Bevort, É., \& Breda, I. (2006). Appropriation des nouveaux médias par les jeunes: une enquête européenne en éducation aux médias. Clemi; European Commission Information Society and Media.

Boyd, D. (2007). Pourquoi les jeunes adore MySPace. Médiamorphoses (21), 69-80.

Brousseau, G. (1988). Le contrat didactique : le milieu. Recherche en didactique des mathématiques , 9 (3), 309-336.

ComScore. (2010, July 21). Génération des 15-24 ans : Décryptage des Usages sur Mobile et sur PC. Retrieved July 29, 2010 from ComScore: http://www.comscore.com/fre/Press_Events/Press_Releases/2010/7/Generation_des_1524_ans_Decryptage_des_Usages_sur_Mobile_et_sur_PC

De Certeau, M. (1984). The Practice of Everyday Life. (S. Rendall, Trans.) Berkely: University of California Press.

Europe's Information Society. (2006, September). Benchmarking Access and Use of ICT in European Schools. Retrieved July 29, 2010 from Europe's Information Society: http://ec.europa.eu/information_society/eeurope/i2010/docs/studies/final_report_3.pdf

Galland, O. (2003). Adolescence, Post-Adolescence, Youth : Revised Interpretations. Revue française de sociologie , 44 (5), pp. 163-188.

Institut national de la statistique et des études économiques. (2009). Taux de scolarisation par âge. Retrieved June 20, 2010 from Institut national de la statistique et des études économiques: http://www.insee.fr/fr/themes/tableau.asp?reg_id=0\&id=146

Jacquinot-Delaunay, G. (2000). Le sentiment de présence. Réseaux Humains / Réseaux Technologiques (pp. 183-191). Poitiers: CNDP.

Kingdon, G. (1998). How much do schools matter to pupil achievement in India? Journal of Educational Plannin and Administration , 12 (1), 5-25.

Lahire, B. (1998). L'homme pluriel. Les ressorts de l'action. Paris: Nathan.

Ministère de l'Éducation nationale. (2009). Repères et références statistiques sur les enseignements, la formation et la recherche. Retrieved July 2010, 29 from Ministère Éducation Nationale: http://media.education.gouv.fr/file/2009/95/5/RERS_2009_FINAL_WEB_117955.pdf

Ministry of Human Resource Development. (2008). Annual Report 2008. Retrieved July 27, 2010 from Government of India - Ministry of Human Resource Development - Department of Higher Education: http://education.nic.in/AR/AR2007-08/AR2007-08.pdf 
Newton, L., \& Rogers, L. (2001). Teaching Science with ICT (Vol. 1). London: Continuum International Publishing Group.

OECD. (2008). Regards sur l'éducation 2008. Note de présentation France. Retrieved February 27, 2009 from OECD: http://www.oecd.org/dataoecd/31/47/41277838.pdf

Pasquier, D. (2005). Cultures lycéennes. La tyrannie de la majorité. Paris, France: Autrement.

Prensky, M. (2001). Digital natives, Digital immigrants. On the Horizon , 9 (5).

Rampal, A. (2005). 'Revaluing' Education. In R. Chopra, \& J. Patricia, Educational Regimes in Contemporary India (pp. 237-255). New Delhi, India: Sage Publications.

Smart Technologies. (2007). La perception des technologies à l'école : Communiqué de presse. Retrieved October 5, 2008 from http://www.infobourg.fr/sections/actualite/actualite.php?id=12173

Thapan, M. (2006). Life at School. New Delhi, India: Oxford University Press.

TNS-SOFRES. (2009, October). Les adolescents, leur téléphone portable et l'Internet mobile. Retrieved June 10, 2010 from TNS-SOFRES: http://www.tns-sofres.com/_assets/files/2009.10.06-adosmobiles.pdf

Weissberg, J.-L. (2000). Entre présence et absence. Réseaux Humains / Réseaux Technologiques. Poitiers: CNDP. 


\section{Tables}

Table 1: Computer access in India in various schools

\begin{tabular}{|l|r|r|r|}
\hline \multicolumn{1}{|c|}{ At home } & \multicolumn{1}{|c|}{$\begin{array}{c}\text { Govt./ Govt. aided / non-elitist } \\
\text { private schools }\end{array}$} & $\begin{array}{c}\text { Private elitist } \\
\text { schools }\end{array}$ & Total \\
\hline Computer for exclusive use & $14.2 \%$ & $37.7 \%$ & $25.2 \%$ \\
\hline Shared computer & $51.7 \%$ & $61.2 \%$ & $56.1 \%$ \\
\hline No computer & $34.1 \%$ & $1.0 \%$ & $18.7 \%$ \\
\hline
\end{tabular}

Table 2: Indian students' representations of school and computers at school

\begin{tabular}{|l|r|r|}
\hline & $\begin{array}{c}\text { \% of students from } \\
\text { elitist private schools }\end{array}$ & $\begin{array}{c}\text { \% of students from } \\
\text { govt-aided schools }\end{array}$ \\
\hline Positive about school & $73.9 \%$ & $72.7 \%$ \\
\hline Positive about computer at school & $79.6 \%$ & $37.3 \%$ \\
\hline Positive about classes & $31.8 \%$ & $41.6 \%$ \\
\hline Classes as the least preferred school activity & $54.2 \%$ & $8.1 \%$ \\
\hline Classes as the most preferred school activity & $4.9 \%$ & $7.1 \%$ \\
\hline $\begin{array}{l}\text { Computer classes as the most preferred school } \\
\text { activity }\end{array}$ & $10.4 \%$ & \\
\hline
\end{tabular}

Table 3: Reasons for going to school according to the Indian students

\begin{tabular}{|l|l|l|}
\hline \multicolumn{1}{|c|}{ Reason 1 } & \multicolumn{1}{|c|}{ Reason 2 } & \multicolumn{1}{c|}{ Reason 3 } \\
\hline $\begin{array}{l}\text { Knowledge, learning } \\
(69,3 \%)\end{array}$ & Interactions $(39,9 \%)$ & Interactions (38\%) \\
\hline Interactions $(14,6 \%)$ & $\begin{array}{l}\text { Knowledge, learning } \\
(22,7 \%)\end{array}$ & Knowledge, learning $(21,8 \%)$ \\
\hline Behavioural learning (5,5\%) & $\begin{array}{l}\text { Behavioural learning } \\
(12,1 \%)\end{array}$ & $\begin{array}{l}\text { Sports, extracurricular activities } \\
(19,3 \%)\end{array}$ \\
\hline Future $(4,4 \%)$ & Future $(6,2 \%)$ & Behavioural learning $(11,4 \%)$ \\
\hline
\end{tabular}


Table 4: Positive and negative aspects of schools as per Indian students

\begin{tabular}{|l|l|}
\hline \multicolumn{1}{|c|}{ Positive aspects- Interviews (out of 24) } & Negative aspects- Interviews (out of 24) \\
\hline Socialisation (19) & Obligation (8) \\
\hline Sports (14) & Routine (7) \\
\hline Learning (11) & Relationships with the peers (6) \\
\hline Personality (7) & Lack of freedom (4) \\
\hline Mix of everything (5) & Tests (4) \\
\hline
\end{tabular}




\section{Figures}

Figure 1: Computer usage in private schools and government schools in India

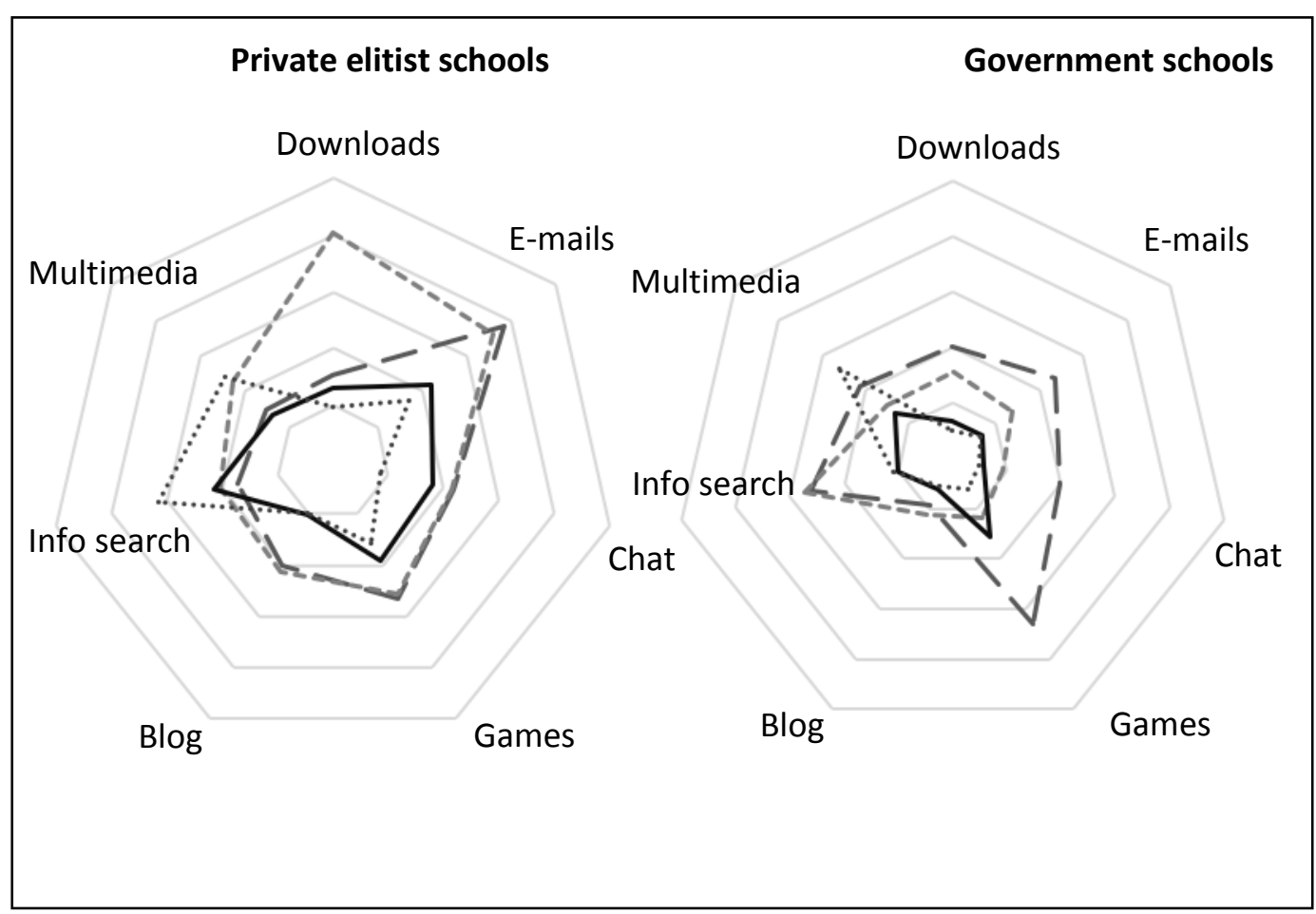




\section{List of Tables}

Table 1: Type of access to computers at home available according to the school one attends

Table 2: Attitude to school and school activities according to the school one attends

Table 3: Reasons for going to school

Table 4: Positive and negative aspects of school

\section{List of figures}

Figure 1: Computer activities in different contexts according to the school one attends 